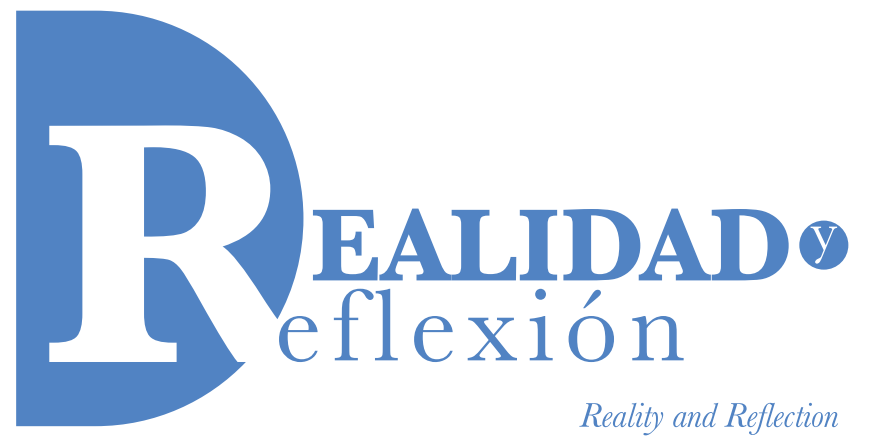

ISSN 1992-6510

e-ISSN 2520-9299

Año 18, N 47, San Salvador, El Salvador, Centroamérica. Revista Semestral Enero-Junio 2018

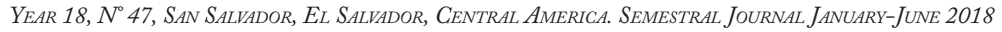

\title{
El impacto de los implantes de los microchips en los Estados Unidos. ¿Esclavitud o beneficio?
}

\section{The impact of microchip implants in the United States. Slavery or benefit?}

\author{
Alicia Urquilla Castaneda \\ Maestría en Creación y Dirección de Empresas de Nebrija Business School \\ Lcda. en Administración de Empresas de Universidad Dr. José Matías Delgado \\ Investigadora Asociada del Instituto de Ciencia, Tecnología e Innovación (ICTI) de la Universidad Francisco Gavidia (UFG) \\ Consultora en diversas áreas empresariales y educativas. \\ aliciaurquicasta@gmail.com \\ Recibido: 10 de diciembre de 2017 \\ Aprobado: 2 de junio de 2018 \\ DOI: http://dx.doi.org/10.5377/ryr.v0i47.6280
}

\section{RESUMEN}

Desde los ataques terroristas del 11 de Septiembre, los poderes que se encuentran no pueden tener suficiente vigilancia sobre nosotros. Lo último en su búsqueda de querer ver cada uno de nuestros movimientos viene en forma de píldoras con un microchip. Este artículo comprende información sobre los diferentes enfoques del uso del microchip en nuestras vidas y lo podemos ir viendo como una realidad por el reciente microchip aprobado por la FDA en una píldora que será la excusa perfecta para colocar la vigilancia dentro de nuestros cuerpos. Al final se brindarán las conclusiones.

Palabras clave: Microchip, microchip de la FDA, implante de chip en humanos, medicina digital.

\section{ABSTRACT}

Since the terrorist attacks of $9 / 11$, the powers that be cannot get enough surveillance on us. The latest in their quest for wanting to watch our every move comes in the form of pills with a microchip. This article includes information on the different approaches to using the microchip in our lives and we can see it as a reality by the recent microchip approved by the FDA in a pill that will be the perfect excuse to place surveillance inside our bodies. At the end the conclusions are presented.

Keywords: Microchip, FDA microchip, chip implant in humans, digital medicine. 


\section{Introducción}

Durante varios años se ha venido prestando atención a diferentes artículos sobre la nueva tecnología en relación a los microchips, pero esta terminología no es entendida por muchos respecto de lo que comprende esta tecnología. Así que se comenzará brindando un resumen de los principales desarrollos relacionados con esta tecnología.

$\mathrm{Su}$ inicio tuvo una apertura inocente. Durante años ha sido una ley en Toronto, Ontario, que todas las mascotas de la casa tienen que tener un microchip para que los propietarios puedan tenerlas ubicadas en caso de que dichas mascotas se alejaran. Luego, en la provincia de Quebec, se aprobó una ley que exigía que todos los animales de granja tuvieran un microchip si querían venderlos en el mercado. Esto era para conocer el pedigrí y para seguir la pista de cada animal desde su nacimiento hasta que fuera sacrificado.

La tarjeta inteligente ha estado en existencia durante varios años. Es del tamaño de una tarjeta de crédito regular, excepto que contiene un microchip del tamaño de un grano de arroz. Es una tarjeta de conveniencia, ya que puede poner su cuenta bancaria en este microchip y comprar y vender con ella en el ocio. Pero por supuesto, si pierde esta tarjeta, perderá la cuenta bancaria que contiene.

Pero fue después de los ataques de 911 que la tecnología de microchips realmente se convirtió para ser utilizada en todo tipo de formas.

\section{La máquina de imágenes digitales}

En mayo de 2002, se informó en Houston, Texas, que los clientes de la tienda Kroger estaban recibiendo sus compras sin efectivo, cheque, ni tarjeta de crédito, pero estaban usando una nueva máquina llamada Secure Touch-n-Pay. Es una máquina de imágenes digitales, conocida oficialmente como un sistema de procesamiento de transacciones electrónicas biométricas. La huella digital se escanea y las compras se cargan automáticamente en su cuenta.

También fue en mayo de 2002 que se anunció que mediante la implantación de electrodos de la anchura de un cabello en los cerebros de las ratas, los científicos estadounidenses crearon roedores controlados a distancia que podrían ser ordenados a dar vuelta, trepar, saltar o navegar por montones de escombros, en avance dicen que algún día podría ayudar en los esfuerzos de búsqueda y rescate.

\section{La nueva tarjeta como documento de identidad}

En septiembre de 2002, se introdujo una nueva tarjeta de identificación (I.D.) que eventualmente se impondrá a todos los ciudadanos de los Estados Unidos. En la parte superior izquierda de esta tarjeta se encuentran las palabras "Identificación de Estados Unidos" con las letras USID. A continuación, aparecen las palabras "Departamento de Seguridad Nacional", bajo el cual se encuentra el número de seguro social, y debajo de eso, la fecha de nacimiento. Entonces, contiene el nombre del individuo con las estadísticas básicas incluyendo la ciudad de la residencia. A la extrema derecha de la tarjeta hay una foto grabada con láser con un dispositivo de identificación por radiofrecuencia en la frente del individuo.

Más de 30 países, desde Italia hasta Malasia, ya han introducido tarjetas de identificación 
"inteligentes" como esta. Los visitantes extranjeros que ahora visitan los Estados Unidos se espera que tengan este tipo de tarjeta para poder entrar en el país.

\section{La VeriChip}

En octubre de 2002, Applied Digital Solutions lanzó una campaña nacional para promover el VeriChip, un microchip del tamaño de un grano de arroz, pero que se puede implantar en seres humanos. Un selecto grupo de personas ya había sido "chipped"1 con dispositivos que automáticamente abren puertas, encienden las luces y realizan otros milagros de bajo nivel.

El investigador Kevin Warwick de la Universidad de Reading en Inglaterra es uno de estos individuos prominentes que es uno de los principales proponentes de los usos potenciales casi ilimitados de tales chips. La familia Jacobs de Boca Raton, Florida, también hizo noticia nacional por haber sido micro-chipped.

\section{Etiquetas RFID}

También hay una nueva tecnología de seguimiento que se utilizará para etiquetar todos los productos en el mundo. El nombre genérico para esta tecnología es RFID, que significa chips de identificación de radiofrecuencia. Las etiquetas RFID se redujeron al principio a la mitad del tamaño de un grano de arena.

E1 14 de febrero de 2007, Hitachi introdujo los chips RFID más pequeños y más delgados del mundo, que miden sólo $0,05 \times 0,05$ milímetros.

\footnotetext{
1 Fragmentado, astillado.
}

En la ilustración 2, el Hitachi mu-chip, es sólo 0,4 x 0,4 milímetros, en el cual se puede observar el tamaño de la etiqueta RFID mu-chip en una yema humana. (La pequeña mancha negra).

Ahora, compare eso con las nuevas etiquetas RFID. Las etiquetas "tipo polvo" son unas sesenta veces más pequeñas (que el reproducido en la imagen de abajo). Los nuevos chips RFID tienen una ROM de 128 bits para almacenar un número único de 38 dígitos, al igual que su predecesor.

Escuchan una consulta de radio y responden transmitiendo su código de identificación único. Al salir de una tienda con artículos que tienen esta etiqueta RFID, los lectores RFID en las puertas registrarán los artículos que compró, facturando automáticamente su cuenta sin el beneficio de dinero en efectivo. Las computadoras en la puerta también recogerán su chip habilitado para GPS para su identificación y coincidirán con el código de e-PC para facturar su cuenta.

Estos dispositivos también podrían utilizarse para identificar y rastrear personas. Por ejemplo, supongamos que usted participó en algún tipo de protesta $u$ otra actividad organizada. Si las agencias policiales rociaron estas etiquetas alrededor, cada individuo podría ser rastreado e identificado más adelante en el ocio con los escáneres de la etiqueta de gran alcance. Este nuevo "polvo" RFID es tan pequeño que puede ser trabajado en cualquier producto, o ser incorporado en papel fino, como el que se utiliza en dinero.

\section{Más micro-chipping de humanos}

En un artículo de Lucien Desjardins, publicado en la edición del 9 de enero de 2007 en "The 
Canadian", los médicos de los Estados Unidos y de Europa se están moviendo en secreto para que el microchip se implante en los recién nacidos. Un doctor de apellido Kilde reveló que el primer ministro Olof Palme de Suecia ya había dado permiso en 1973 para implantar prisioneros, y el exdirector general de Data Inspection, Jan Freese, reveló que los pacientes de hogares de ancianos fueron implantados a mediados de los años ochenta.

Una cosa mala sobre tener un microchip implantado en uno mismo es el hecho de que uno podría entonces ser seguido dondequiera en el mundo. Según el Dr. Kilde, "los microchips de hoy en día operan por medio de ondas de radio de baja frecuencia que se dirigen a ellos. Con la ayuda de los satélites, la persona implantada puede ser rastreada en cualquier parte del mundo". Según el Dr. Kilde, las funciones cerebrales también pueden ser controladas remotamente por superordenadores e incluso alteradas a través del cambio de frecuencias.

\section{El plan global}

Hace unos años (2007), el director de Hollywood y director de cine documental Aaron Russo declaró en una entrevista radial que Nick Rockefeller le pidió que se uniera al Consejo de Relaciones Exteriores (CFR). Russo se negó, pero le preguntó a Rockefeller: "¿Cuál es el punto de todo esto? Usted tiene todo el dinero en el mundo que necesita, tiene todo el poder que necesita, así que ¿cuál es el punto, cuál es el objetivo final?" Rockefeller respondió (parafraseando): "El objetivo final es hacer que todos tengan un microchip, controlar a toda la sociedad, hacer que los banqueros y las élites controlen el mundo".

Algunos pueden argumentar que no hay manera de que las poblaciones enteras acepten tener un microchip, que suena demasiado como una fantasía de ciencia ficción. Sin embargo, sabemos que esto es exactamente lo que el programa de la gente del mundo es.

\section{Posibles enfoques}

Entonces, ¿qué tipo de enfoque tomarán para hacernos aceptar el microchip? Kevin Haggerty escribió un artículo titulado Una generación es todo lo que necesitan en el número del 10 de diciembre de 2006 del The Toronto Star, dando un escenario de chips que primero se implantan en miembros de grupos estigmatizados como pedófilos, terroristas, narcotraficantes, lo que la gente de la sociedad considera que es lo peor de lo peor. Entonces los individuos acusados serán etiquetados para detenerlos de huir de la justicia. Los prisioneros acogerán con satisfacción este desarrollo, ya que sólo los reclusos con chip serán elegibles para libertad condicional, libertad de fin de semana o condenas comunitarias.

Pero esto sólo cubrirá un segmento pequeño de la sociedad. Por lo tanto, hay que orientar a otros grupos estigmatizados, como los de bienestar, por ejemplo. Los beneficiarios del bienestar tendrán que ser monitoreados para reducir el fraude, aumentar la eficiencia y para asegurar que los pobres no reciban beneficios "inmerecidos".

Los empleadores comenzarán entonces a esperar que los implantes sean una condición para conseguir un trabajo. Los militares 
estadounidenses liderarán el camino al requerir fichas para todos los soldados como un medio para mejorar el control y el mando del campo de batalla - e identificar restos humanos.

Entonces seguirá el masivo sector de la seguridad. Se espera que los guardias de seguridad, oficiales de policía y trabajadores correccionales tengan un chip. Los individuos con trabajos sensibles se encontrarán en la misma posición. Los medios probablemente construirán un caso sobre un niño que fue secuestrado y abusado o asesinado para que los padres quieran que todos sus hijos tengan un chip. Los hospitales entonces comenzarán a requerir un chip para recibir tratamiento médico.

Ofertas especiales se ofrecerán a los que tengan un chip. Las empresas ofrecerán descuentos a las personas que pagan utilizando los fondos almacenados en su chip incorporado.

La tecnología doméstica nueva requerirá un chip para operar los electrodomésticos cotidianos. Encontrar una computadora o un dispositivo que se ejecute a través de la antigua tecnología "hands-on" se hará progresivamente más difícil. Tener un chip casi tendrá que ser una necesidad para participar en la dinámica principal de la vida moderna, como ir de compras y conducir.

Aquellos que se nieguen a tomar el chip serán acusados de tratar de ocultar algo. También tendrán que lidiar constantemente con retrasos e inconvenientes reservados para los que no poseen un chip.

Entonces, como último recurso, aquellos que todavía se niegan a tomar el chip serán declarados enemigos del estado y llevados a campos especiales donde serán torturados e incluso asesinados si no se someten a este plan que requerirá a todos los habitantes de la tierra tener un chip. Así que lo que podría comenzar como una cosa supuestamente buena terminará convirtiéndose en una forma de esclavizar a la humanidad.

\section{FDA aprueba venta de píldoras con RFID microchip}

Desde el principio y el final se cubrió que el Reino Unido aprobaba las píldoras de la prescripción que contenían microchips del RFID. Ahora la Administración de Alimentos y Drogas de los Estados Unidos ha aprobado un medicamento microchip RFID ingerible similar para su uso en los EE.UU.

La Administración de Drogas y Alimentos ha aprobado un ingrediente digital que puede rastrear la salud física con la afirmación de que los pacientes no están tomando su medicación regularmente y necesitan un dispositivo de rastreo dentro de su cuerpo para ayudarles en su atención médica.

Proteus Digital Health (PDH) lanzó el marcador de eventos de ingestión (IEM) que fue aprobado por primera vez en Europa. George Savage, cofundador y director médico de PDH afirma que esto lleva a una nueva era de la medicina digital que "cambia el paradigma". El IEM, tan pequeño como un grano de arena, puede ser incrustado en una píldora, y se ingiere para controlar al paciente y su salud corporal. El dispositivo recogerá mediciones tales como ritmo cardíaco, posición corporal y actividad. 
E1 IEM envía una señal a su teléfono inteligente; Que luego transmite los datos a su médico. Los datos reales en tiempo real sobre su maquillaje biológico se pueden cargar de forma inalámbrica.

De acuerdo a Eric Topol, MD, profesor de genómica en el Scripps Research Institute en La Jolla, California, dijo en un comunicado de prensa que "La validación de la FDA representa un hito importante en la medicina digital. La digitalización directa de píldoras, por primera vez, junto con la infraestructura inalámbrica que poseen, puede resultar ser el nuevo estándar para influir en la adherencia a los medicamentos y ayudar significativamente a la gestión de enfermedades crónicas", E1 Dr. Topol es el autor de la destrucción creativa de la medicina: Cómo la revolución digital creará una mejor atención sanitaria.

El sistema de retroalimentación digital de Proteus combina un sensor ingerible colocado en una píldora, con un sensor portátil en un parche adhesivo y una aplicación móvil que muestra datos en un dispositivo móvil, como un teléfono inteligente.

El sistema de retroalimentación de Proteus Digital Health integra tecnologías de sensores usables e ingeribles para detectar la ingesta de medicamentos y los datos fisiológicos. Un parche desechable se usa en el cuerpo para capturar y transmitir la respuesta fisiológica del cuerpo y los comportamientos. Además de registrar la información del sensor, el parche registra la frecuencia cardíaca, la temperatura, la actividad y los patrones de descanso. E1 parche dura aproximadamente 7 días y es operado por una batería, que también dura aproximadamente 7 días.
A continuación, se lleva un dispositivo móvil en el bolsillo o bolsa para mostrar los datos en contexto y el cuidado de soporte. El sensor puede utilizarse para detectar el momento exacto en que se toma la medicación, así como la identidad única del medicamento. La información es controlada por el paciente.

E1 IEM no contiene una batería. En su lugar, los fluidos del estómago alimentan el sensor y el cuerpo transmite la señal digital generada por el sensor. El IEM es el único sensor ingerible alimentado por el cuerpo. El sensor pasa a través del cuerpo similar a la fibra.

El sistema, que solía ser conocido como el Sistema Raisin, recibió la aprobación reguladora europea en agosto de 2010. La tecnología ha sido utilizada durante miles de días por los pacientes en ensayos clínicos sin eventos adversos graves. El sistema no parece interferir con otros dispositivos médicos.

\section{Otras experiencias de las primeras etiquetas RFID de los EE. UU. que pueden implantarse en humanos}

Los chips de RFID de $134.2 \mathrm{KHz}$ podrían salvar vidas y posiblemente limitar las lesiones por errores en tratamientos médicos, según VeriChip Corp., una subsidiaria de Applied Digital Solutions Inc.

VeriChip cree firmemente en la viabilidad del chip que lo ha probado en uno de los suyos: El vicepresidente de aplicaciones médicas de la compañía, el Dr. Richard Seelig. Cuando Seelig renunció a su práctica médica en Nueva Jersey en 2001 para trabajar en VeriChip, no tenía ni idea 
de que un día implantaría bajo su piel dos chips RFID para localizar perros. "No se me ocurrió hasta el ataque terrorista del 11 de septiembre", dice Seelig. "Eso es lo que me motivó a llevar el proyecto a otro nivel".

Los chips podrían facilitar el acceso a la información médica para personas con enfermedades potencialmente mortales, y podrían ser particularmente útiles durante una crisis médica, según la compañía. "Autoriza a las personas a conocer y manejar sus problemas de atención médica en una situación de emergencia en un momento muy crítico", dice Seelig. También podría utilizarse para realizar un seguimiento de otros dispositivos implantables, como un marcapasos, que podría tener un paciente. La etiqueta podría alertar a los médicos de los implantes durante la cirugía y transmitir la información necesaria sobre los implantes, como el tamaño y el fabricante. Además, los pacientes podrían permanecer mejor informados en caso de que algún dispositivo se retire.

VeriChip sugiere que el chip se inserte en la parte trasera del tríceps del brazo derecho debajo de la piel. La compañía planea comercializar el chip por \$125 (sin incluir la implantación). El chip no contiene ningún registro médico, pero su número de 16 dígitos podría estar vinculado a una base de datos de información médica del paciente. Cuando se escanea la etiqueta, el número puede ser rápidamente cruzado para revelar datos médicos específicos sobre el paciente.

Las etiquetas son similares a las que se insertan en el ganado y las mascotas como una forma de identificación para rastrear la enfermedad de la vaca loca o la tuberculosis.
Aunque aún no se tiene nada en concreto, se ha confirmado que en México, la empresa VeriChip estableció en una institución pública a un total de 160 de sus empleados haber recibido chips implantados por ellos, y que se usarían para controlar el acceso a habitaciones y documentos considerados vitales en la lucha de México contra los cárteles de la droga.

\section{Identificación por radiofrecuencia (RFID). Descripción}

Identificación de radiofrecuencia (RFID) se refiere a un sistema inalámbrico compuesto de dos componentes: etiquetas y lectores. El lector es un dispositivo que tiene una o más antenas que emiten ondas de radio y reciben señales de la etiqueta RFID. Las etiquetas, que utilizan ondas de radio para comunicar su identidad y otra información a los lectores cercanos, pueden ser pasivas o activas. Las etiquetas RFID pasivas son alimentadas por el lector y no tienen una batería. Las etiquetas RFID activas se alimentan con baterías.

Las etiquetas RFID pueden almacenar un rango de información de un número de serie a varias páginas de datos. Los lectores pueden ser móviles para que puedan ser llevados a mano, o pueden ser montados en un poste o gastos generales. Los sistemas de lectura también se pueden incorporar a la arquitectura de un gabinete, una habitación o un edificio.

\section{Usos}

Los sistemas RFID utilizan ondas de radio en varias frecuencias diferentes para transferir datos. En la atención de la salud y la configuración 
hospitalaria, las tecnologías RFID incluyen las siguientes aplicaciones:

- Control de inventario.

- Seguimiento de equipos.

- Detección fuera de la cama y detección de caídas.

- Seguimiento de personal.

- Garantizar que los pacientes reciban los medicamentos y dispositivos médicos correctos.

- Prevención dela distribución de medicamentos falsificados y dispositivos médicos.

- Monitoreo de pacientes.

- Proporcionar datos para los sistemas de registros médicos electrónicos.

La FDA no tiene conocimiento de ningún evento adverso asociado con RFID. Sin embargo, existe la preocupación por el riesgo potencial de interferencia electromagnética (EMI) a dispositivos médicos electrónicos de transmisores de radiofrecuencia como RFID. EMI es una degradación del rendimiento de los equipos o sistemas (como los dispositivos médicos) causada por una perturbación electromagnética.

\section{¿Los implantes de microchip en seres humanos serán obligatorios algún día?}

Según investigadores en el tema los microchips implantados en el ser humano no sólo serán populares en el futuro sino que serán obligatorios.
Por otra parte, si su visión del futuro es correcta, casi nadie tendrá que ser arrastrado dando patadas y gritando por los soldados de la tormenta (o robots) en ese nuevo mundo valiente; por el contrario, la mayoría de las personas estarían dispuestos a tener un chip.

De hecho, el movimiento ya está en marcha. En varios lugares del mundo, hay personas que abren puertas, ponen en marcha automóviles y controlan sus computadoras con un mero gesto de sus manos o brazos.

Ellos están entre la primera ola de personas que han permitido voluntariamente un chip de computadora en miniatura para ser colocado dentro de sus cuerpos. La mayoría es parte de un grupo que aboga por el biohacking, un concepto en el cual los activistas buscan mejorar el cuerpo humano a través del uso de la tecnología.

Muchos biohackers también se identifican con un movimiento más amplio conocido como transhumanistas. Los transhumanistas creen que la gente finalmente será capaz de transformarse a sí misma a través del uso de la tecnología en seres superiores que poseen capacidades ampliadas. Los adherentes del movimiento categorizan a tales individuos como "posthumanos".

Al avanzar hacia una humanidad recién definida, se está inyectando un pequeño chip de identificación de radiofrecuencia (RFID) en la mano, muñeca o brazo de un individuo mediante el uso de una aguja hipodérmica de la misma manera que una vacuna de rutina. E1 microchip implantado transmite un número o código de identificación, que puede usarse para una miríada de propósitos. 
Los beneficios de esta tecnología son seductores: no más tener que llevar - y preocuparse por perder - numerosas tarjetas de crédito y otras formas de identificación. No más torpes para ellos al realizar transacciones; Una ola de la mano será suficiente. No muestre pasaportes cuando viaja o su licencia de conducir a un policía. Y puesto que el microchip facilitaría una sociedad sin dinero, no habría más preocupaciones sobre la pérdida o el robo del efectivo, y podría poner fin a la droga del mercado negro y a otras transacciones ilegales; el robo de identidad podría ser eliminado, también (aunque cualquier tecnología podría concebiblemente ser eludida). Y como Lain Gillespie escribió en el Sydney Morning Herald, "Los implantes envían un número de identificación único que se puede usar para activar dispositivos como teléfonos y candados, y puede enlazar a bases de datos que contienen información ilimitada, incluyendo datos personales como nombres, direcciones y registros de salud".

Gillespie también mencionó al científico cibernético Dr. Mark Gasson de la Universidad de Reading (UR) del Reino Unido, quien recientemente hizo historia: Después de implantarse un chip en sí mismo en 2009 para controlar los aparatos electrónicos de su oficina, se convirtió en el primer humano infectado con un virus informático. "El virus fue replicado en las tarjetas de acceso del personal que accedía a su edificio e infectó la base de datos de la universidad", según Gillespie.

Sin embargo, Gasson sigue entusiasmado con lo que él caracteriza como una inevitable e inminente nueva tecnología normal. Él dice: "Tiene el potencial de cambiar la esencia misma de lo que es ser un humano". Él cree que la aceptación de los microchips será la misma que la de los teléfonos móviles y que se desarrollará una situación en la que "será una desventaja para los que no tienen el implante que esencialmente no será opcional”.

Pero se vuelve aún más extraño. Como Gillespie también escribió:

En el año 2013 la línea entre el hombre y la máquina se hizo aún más borrosa, cuando la Universidad de Stanford anunció que sus científicos habían creado el primer transistor puramente biológico que fue hecho enteramente del material genético.

El profesor asistente de bioingeniería de Stanford, el Dr. Drew Endy, describió el avance como el componente final necesario para un ordenador biológico que puede operar dentro de las células vivas y reprogramar los sistemas vivos.

$\mathrm{Y}$ hasta cierto punto el futuro es ahora, con la tecnología biométrica que ya se está utilizando en ciertas aplicaciones a gran escala. Como nos informa el escritor Michael Snyder, se está probando un método de pago escaneado a mano en el sur de Suecia, los escáneres biométricos / dispositivos de rastreo RFID ya se usan en comedores universitarios y algunos parques de diversiones, y la tecnología está incluso siendo utilizada en África para mantener un seguimiento de quién está siendo vacunado”.

Después de todo, su teléfono celular tiene un chip RFID y se puede utilizar para realizar un seguimiento de cada movimiento, y su cámara puede ser remotamente activada por las 
autoridades. Y todos tenemos números de Seguro Social. Pero el paso hacia el estatus obligatorio comenzará dentro de muy poco tiempo es lo que aseguran los expertos en el tema, a continuación:

Primero, las tecnologías tendrán que ser aceptadas generalmente por la sociedad. Comenzará con productos basados en el consumidor en tiempo real como Google Glass. Las generaciones más viejas pueden rechazarlo, pero en un par de años usted puede apostar que decenas de millones de niños, adolescentes y adultos jóvenes estarán vagando por las calles mientras se disfrutan nuevas modalidades, navegación web interactiva y la capacidad de grabar todo a su alrededor y subirlo a la Internet al instante.

Recuerde que a los jóvenes les gusta especialmente la sensación de estar "con la última tecnología", a la vanguardia, y no quieren tener tecnología anticuada más que ropa fuera de moda; saltarán para tener un chip apenas mientras que arrebatan para arriba el último teléfono elegante. Y no sólo la tecnología será conveniente, sino que les dará una ilusión de poder. Con sólo levantar su mano se abrirán las puertas para usted - literal y figurativamente.

Eventualmente, una vez que el concepto sea generalmente aceptado por la mayoría, se convertirá en nuestro nuevo número de seguridad social. Por lo tanto, necesitará un chip para beneficiarse de los servicios del gobierno $\mathrm{y}$, tarde o temprano, para hacer una compra (de nuevo, la sociedad, sin duda, se convertirá en dinero en efectivo).

\footnotetext{
2 Doble más dinero.
}

3 Un mundo feliz.
En ese momento las circunstancias pueden obligar a una persona a aceptar un implante, incluso si el gobierno no lo hace. $Y$ las implicaciones de esto son graves, dicen muchos críticos. Por ejemplo, la profesora de la Universidad de Wollongong Katina Michael advierte, informa Gillespie:

"Los microchips RFID son esencialmente un ID único incrustado en su cuerpo, y, como sabemos, los números pueden ser robados $\mathrm{y}$ los datos pueden ser hackeados. Ellos apuntan a una sociedad de vigilancia Uber que es hermano mayor en el interior mirando hacia fuera. Los gobiernos o las grandes corporaciones tendrían la capacidad de rastrear las acciones y los movimientos de las personas... y en última instancia incluso controlarlas".

También hay que tener en cuenta que con el gobierno estadounidense desarrollando la capacidad de predecir el comportamiento de un individuo con algoritmos informáticos y con la ciencia comenzando a crear una tecnología que pueda descifrar pensamientos e intenciones (lectura de la mente), el futuro parece, bien, bastante revelador.

¿Así vendrá un día en el que nos atrevemos a pensar sólo en los pensamientos de "doubleplusgood"? 2 ¿1984 y Brave New World pasarán de la ficción a la noticia? Cualquiera que sea el caso, podemos decir sin titubear algo sobre la vieja maldición china: "Que vivas en tiempos interesantes":

\section{Resultados de encuesta realizada para implantes en los cerebros}

Encuesta muestra que el 34 por ciento de los estadounidenses están entusiasmados con la 
perspectiva de microchips implantados en sus cerebros.

Más de un tercio de los estadounidenses están "entusiasmados" con la posibilidad de tener microchips implantados en sus cerebros, según una encuesta reciente.

Pew Research Center encuestó a 4.726 adultos 47 de los cuales acordaron participar en grupos de discusión - para discernir sólo lo bien que podrían ser los putativos avances biomédicos, pero donde el público se apoya en cuestiones éticas y morales inherentes a su uso.

El Pew Research Center acaba de publicar los resultados de una encuesta que llevó a cabo para averiguar cómo se sentían los estadounidenses sobre el uso de "mejoras" biomédicas actualmente en desarrollo.

Se pidió a los participantes en la encuesta que leyeran el siguiente texto antes de responder a una serie de preguntas:

"Los nuevos desarrollos en la comprensión del cerebro están creando la posibilidad de que los médicos serán capaces de implantar quirúrgicamente un pequeño chip de computadora en el cerebro. En estos momentos, estos dispositivos implantados se están desarrollando para las personas con algún tipo de enfermedad o discapacidad. , Estos dispositivos implantados podrían estar disponibles para su uso por personas sanas, dando a las personas una capacidad mucho mejor de concentrarse y procesar la información en la vida cotidiana".

4 Agencia de Proyectos de Investigación Avanzada de Defensa.
¿Se están entrometiendo con la naturaleza?

Aunque el 41\% de los encuestados dijo estar "algo" preocupado por los efectos potenciales de esa tecnología, mientras que otro $28 \%$ dijo que estaba "muy" preocupado, un número sorprendente de personas dijeron que estaban "algo" (25\%) o "muy "(9\%) entusiasmados con el concepto.

Aproximadamente dos tercios de los estadounidenses dijeron que no estarían interesados en usar esta tecnología para sí mismos, pero el 32\% dijo que querría esos implantes si realmente pudieran mejorar su función cerebral.

Mientras que la mayoría (61\%) de los estadounidenses admitieron que nunca habían sido conscientes que tal tecnología podría existir, aquellos familiarizados con los implantes cerebrales estaban más dispuestos a abrazar el concepto.

Las personas religiosas eran mucho menos propensas a aceptar la idea de los implantes cerebrales, por ejemplo, el $51 \%$ de los adultos religiosos estadounidenses dijo que para ellos esa tecnología sería moralmente inaceptable y constituiría "entrometerse con la naturaleza".

Entre los ateos y los agnósticos, los porcentajes de los partidarios eran mucho más altos: $58 \%$ de los ateos y $48 \%$ de los agnósticos dijeron que estarían interesados en recibir implantes cerebrales.

\section{El factor DARPA ${ }^{4}$}

Uno puede asumir razonablemente que la gente en DARPA - que han gastado \$62 millones que investigan la tecnología del implante del cerebro 
del microchip - está examinando los resultados de la encuesta de Pew con gran interés.

La Agencia de Proyectos de Investigación Avanzada de Defensa (DARPA) parece estar a punto de perfeccionar un dispositivo de codificación neural que "abrirá el canal entre el cerebro humano y la electrónica moderna".

DARPA ya ha probado con éxito sus propios microchips de implantes cerebrales en animales, y los ensayos en seres humanos están programados para comenzar en 2017.

Los dispositivos de codificación neural que están siendo desarrollados por DARPA están ostensiblemente diseñados para controlar extremidades artificiales, pero parece obvio que su potencial es mucho mayor. Como admitió DARPA, la tecnología será capaz de permitir "el ancho de banda de transferencia de datos entre el cerebro humano y el mundo digital, alimentando información auditiva o visual digital en el cerebro".

En otras palabras, tales implantes serían dispositivos de lavado de cerebro extremadamente eficaces que podrían ser utilizados con igual facilidad para controlar a las personas, así como a miembros protésicos.

La tecnología de los implantes cerebrales tiene el potencial de mejorar las vidas de aquellos con ciertas discapacidades, pero ¿estamos realmente preparados para un futuro en el cual las personas normales y saludables reciben - voluntariamente o no - implantes cerebrales que podrían "mejorar" la función mental de una persona o quizás Incluso disminuirlo?
Los efectos negativos potenciales y los usos siniestros de tal tecnología parecen ser significativos, pero parece que hay un montón de gente que estará feliz de asumir el riesgo.

Por supuesto, los medios de comunicación están ayudando a prepararnos para nuestro futuro distópico, junto con magnates de las redes sociales, como el CEO de Google, Eric Schmidt, que apoya la agenda de DARPA y la idea de usar tales dispositivos para monitorear los pensamientos del público.

En una conferencia de Bilderberg, Schmidt dijo - con respecto a la tecnología de lectura mental de DARPA - que si "tienes algo que no quieres que nadie sepa, tal vez no deberías hacerlo en primer lugar".

\section{Conclusiones}

No lo suficientemente contentos con la supervisión de nuestras llamadas telefónicas, computadoras y tener una cámara en nosotros en todas partes vamos afuera. El recientemente aprobado por la FDA microchip en una píldora será la excusa perfecta para colocar la vigilancia dentro de nuestros cuerpos.

Sí, es ciencia-ficción como en el ejemplo de la antigua película de George Lucas THX 1138 ahora convertida en ciencia-hecho. La dictadura científica es aquí el cuidado de la vigilancia estatal.

Por supuesto, la idea nos será presentada como muy beneficiosa desde el punto de vista de la salud. Que la gente puede ser revisado si han tomado sus píldoras y no olvidarse de ellos o el 
uso de monitoreo en tiempo real para mantener la dosis correcta prescrita y mucha gente va a comprar en él, mientras que no puede ver el posible oscuro motivo oculto escondido.

¿Podría un sistema de control digital de dosificación con control remoto tener el efecto de hacer que sus ciudadanos tomadores de píldoras sean templados y dóciles si es necesario? ¿O podría usarse para cambiar deliberadamente nuestros estados de ánimo?

Una pista en la agenda oculta viene del hecho de que estas píldoras micro-chipped han costado miles de millones para desarrollarlas, lo que viene al punto de que el gobierno podría tener mucho interés en que se implementen en los seres humanos.

La falta de vigilancia a través del microchip interno no es nada nuevo. Regina Dugan, una ex directora de DARPA que se convirtió en Google Executive, se conoce desde hace algún tiempo por querer hacer tragar a las personas microchips de identificación. Ella también ha estado empujando para que se implemente un tatuaje electrónico capaz de leer la mente.

Los que lo desarrollan afirman que ayudará a las personas con problemas mentales como por ejemplo los soldados que quieren tener malos recuerdos borrados de estar en el campo de batalla. Pero las consecuencias de esto también podrían tener oscuros y siniestros motivos ocultos cuando se utiliza para el control de la mente.

Esto en efecto convierte a la persona que ingiere estos microchips en un sistema de identificación biológica. Esto les permite usar sus computadoras, teléfonos y abrir las puertas de su coche, etc., como parte del "sistema inteligente", pero la idea de usar estas nuevas tecnologías para el oscuro y siniestro propósito de ser rastreado y monitoreado es una violación de las libertades y libertad individuales.

El hecho de que las autoridades relacionadas que supervisan esta tecnología ha mentido frecuentemente al expresar que no están interesados en fisgonear en las llamadas de telefónicas, etc., cuando es lo contrario, se ha encontrado bastante para enviar una advertencia de la bandera roja en microchip de las personas con las píldoras.

La tecnología del microchip ha estado años en la fabricación. La recopilación de metadatos de inteligencia geoespacial por más de 15 años se ha utilizado para trazar el comportamiento humano para la vigilancia masiva ... No debe sorprender a nadie que las potencias que se han tomado esto muy en serio sabiendo que quieren utilizar la vigilancia en una escala global.

\section{Recursos bibliográficos}

Blacklistednews. (2016). A third of US Adults saye they'd be enthusiastic about having a microchip implanted in brain. Recuperado de: http://www.blacklistednews.com/A_Third_ of_U.S._Adults_Say_They'd_Be_'Enthusiastic'_ About_Having_a_Microchip_Implanted_in_ Brain/53014/0/38/38/Y/M.html

Funk, C., Kennedy, B., Podrebarac, E. (2016). Public opinion on the future use of brain implants. Pew Research Center. http://www.pewinternet. org/2016/07/26/public-opinion-on-the-futureuse-of-brain-implants/ 
Landau, E. (s.f.). Just give it to me in a chip. CNN. Masand, P.S., Roca, M.,Turner, M., Kane, Recuperado de: http://www.cnn.com J. (2009) Prim care companion. J Clin Psychiatry.11(4):147-54.

Lehman, A., Lieberman, J., Dixon, L., McGlashan, T., Miller, A., Perkins, D. (2004)., Sabaté, E. (2003). Adherence to long-term therapies: Practice guideline for the treatment of patients with schizophrenia, second edition. Am J Psychiatry.161 (2 Suppl): 1-56.

Luga, A., McGuire, M. (2014). Adherence and evidence for action. Geneva, Switzerland: World Health Organization.

White, G. (2016). DARPA spent 62 million creating microchips for humans. Glitch.news. Recuperado de: http://www.glitch.news/201607-22-darpa-spent-62-million-creatingmicrochips-for-humans.html 